\title{
LA UNIVERSIDAD ESPAÑOLA: ENTRE EUROPA Y UNA AUTONOMÍA TRAMPOSA
}

\author{
Francisco Sosa Wagner \\ Catedrático de Derecho Administrativo \\ Universidad de León
}

\begin{abstract}
RESUMEN
En este trabajo se analiza la situación actual de la universidad española partiendo de las reformas introducidas en los años ochenta del pasado siglo, momento que coincide con la incorporación de España a las instituciones europeas. ¿Cómo ha afectado a la universidad el precepto constitucional que instituyó la autonomía universitaria? ¿Qué conflictos judiciales ha provocado? ¿Cómo se pueden valorar los actuales órganos de Gobierno de las universidades españolas? ¿Qué reflejo ha tenido el proyecto europeo en los hábitos de los profesores y estudiantes españoles?
\end{abstract}

Palabras clave: educación superior; autonomía universitaria; Europa; Erasmus; profesorado universitario; estudiantes universitarios; planes de investigación.

\begin{abstract}
The author analyzes the current situation of the Spanish university from the reforms introduced in the eighties of the last century. This time coincides with the incorporation of Spain to the European institutions. How has it affected the university the constitutional precept that credited 'autonomy'? What has the judicial conflict been triggered? How can you assess the current Government of the Spanish universities? What reflexes has European project had in the habits of Spanish teachers and students?
\end{abstract}

Key words: higher education; university autonomy; Europe; Erasmus; university faculty; university students; research plans. 


\section{SUMARIO}

I. La AUTONOMía COMO MALETA DE DOBLE FONDO.-II. El LUGAREÑo EN SU RINCÓN: LA SELECCIÓN DEL PROFESORADO.-III. LA LEY DEL EMBUDO: ESTATUTOS Y REGLAMENTOS DE LAS UNIVERSIDADES.-IV. EUROPA O EL LUGAR DONDE SE PIERDE EL PELO DE LA DEHESA.-V. EL HONOR PERDIDO DEL CONSENSO.

\section{LA AUTONOMÍA COMO MALETA DE DOBLE FONDO}

Nuestro ingreso en la Comunidad Económica Europea (1985) se debió a que en España se había instaurado un sistema democrático regido por una Constitución parecida a las existentes en los países que, a partir de ese momento, se convirtieron en nuestros socios de aventura histórica.

En ella aparece la autonomía universitaria (art. 27. 10) como aparecen la libertad de enseñanza (párrafo primero del mismo precepto) y la de cátedra (art. 20). Después vino la legislación del Estado: frustrados varios intentos parlamentarios, llegamos a 1983 y es justamente el esforzado legislador veraniego (la ley es del tranquilo agosto madrileño) quien nos aclara lo que albergaba en su panza esa idea (art. 3.2) y que esta, la benemérita autonomía, «exige y hace posible que docentes, investigadores y estudiantes cumplan con sus respectivas responsabilidades en orden a la satisfacción de las necesidades educativas, científicas y profesionales de la sociedad» (art. 2.2).

Bullicio de palabras ciertamente, hojarasca en prosa legal.

Fundamento de la actividad universitaria es - y aquí hay mayor precisión- la «libertad académica» manifestada en las libertades de cátedra, de investigación y de estudio (art. 2.1).

Pronto llegaría la jurisprudencia para colmar las alegrías del lenguaje. Y así no tardaría en decir el TC que la libertad académica tiene dos vertientes (Sentencia 26/1987 de 27 de febrero), una colectiva o institucional, constituida por la autonomía universitaria, y otra individual, compuesta por la libertad de cátedra. Ambas «sirven para delimitar ese espacio de libertad intelectual sin el cual no es posible la creación, desarrollo, transmisión y crítica de la ciencia, de la técnica y de la cultura que constituye la última razón de ser de la Universidad». Y, respecto de la libertad de cátedra, ya con anterioridad a la aprobación de ese texto legal, la Sentencia del TC 5/1981 de 13 de febrero la había definido como «el derecho de quienes llevan a cabo personalmente la función de ense- 
ñar, a desarrollarla con libertad dentro de los límites del puesto docente que ocupan», por lo que constituye una «libertad individual del docente, a quien depara un espacio intelectual resistente a injerencias compulsivas impuestas externamente».

Pero vayamos a la autonomía y a la configuración que de ella se hace por el TC en su Sentencia citada 26/1987: la autonomía es un «derecho fundamental por su inclusión en la sección primera del capítulo segundo del Título I, por los términos utilizados en la redacción del precepto, por los antecedentes constituyentes del debate parlamentario que llevaron a esa conceptuación y por su fundamento en la libertad académica, que proclama la propia LRU».

La opinión mayoritaria del Tribunal (confirmada después en diversas ocasiones desde la Sentencia 55/1989 de 23 de febrero) sirvió en bandeja la confusión de la autonomía con las libertades específicas y, muy en singular, con la libertad de cátedra. Y además añadió la confusión entre derecho fundamental y garantía institucional como se advierte en sus propias palabras: "lo primero que hay que decir es que derecho fundamental y garantía institucional no son categorías incompatibles o que necesariamente se excluyen, sino que buena parte de los derechos fundamentales que nuestra Constitución reconoce constituyen también garantías institucionales...».

Sabemos que al final, pese a estos escrúpulos metodológicos, y a la hora de elegir entre ambos conceptos, el TC se decantó por la idea del «derecho», lo que dio lugar a un animado debate doctrinal.

Como no es mi intención castigar al lector dejándolo perdido en el vericueto de los pronunciamientos judiciales, retengamos aquí simplemente las ideas de las Sentencias 106/1990 y 187/1991, que se repiten en la 47/2005 o en la 87/2014: «la autonomía — de estricta configuración legal- no está más que al servicio de la libertad académica en el ejercicio de la docencia e investigación...».

Convengamos que la almendra de la cuestión son estas libertades y no una forma organizativa concreta. Lo trascendental es la libertad individual de investigación y de docencia, no un pretendido derecho fundamental ni una garantía institucional de la organización. Se trata de amparar derechos cuya titularidad corresponde a personas concretas, el docente, el investigador. Dejemos, pues, de hablar de derechos de organizaciones, de entes abstractos o de "comunidades universitarias» y pasemos a hacerlo de las personas que en ellas enseñan, investigan o aprenden. Es decir, volvamos a los clásicos y repitamos que el hombre sigue siendo la medida de todas las cosas, tal como enseñó el viejo Protágoras. 
Porque la libertad de investigación, también llamada libertad científica, o sin más libertad de cátedra, es un típico derecho individual (de él son titulares personas físicas) de origen liberal, emparentado con la libertad de expresión, que ha de ser comprendido como el círculo de defensa, individual y subjetivo, frente a poderes ajenos, a su vez reflejo de una concepción de los valores culturales de las sociedades contemporáneas. Su trascendencia es tan relevante que obliga al Estado (y, en general, a todos los poderes públicos) a actuar - y actuar de manera positiva - para protegerla: garantizando la pluralidad y la neutralidad, excluyendo el dirigismo y las injerencias. Asegurando, en fin, los medios para hacerla realidad. Se trata de una libertad con un contenido variable porque el objeto que ha de preservar está abierto a las cambiantes exigencias del desarrollo y de las condiciones de vida en el mundo. Un derecho que exige, pues, una interpretación acorde a las circunstancias enormemente sensibles en las que, como valor constitucional, se ve obligado a operar y ello porque la ciencia es un concepto extrajurídico procedente de campos muy diversos, que son aquellos donde se desarrolla la vida en el planeta, en sus vertientes espiritual y material.

Su frontera se halla en la reflexión porque la ciencia no incluye la acción concreta ni la adopción de determinadas conductas, menos aún las decisiones políticas, es decir, la propaganda o la agitación, el adoctrinamiento no están protegidos por la libertad de la que aquí hablamos. Por su parte, la pluralidad implica que la investigación es un espacio abierto y por ello no vinculado a más valores que los éticos básicos (en esto consiste la neutralidad). Incluso aquellos valores que están patrocinados por el texto constitucional pueden ser puestos en cuestión por el investigador siempre que se mantenga en los límites del trabajo teórico y en términos de discrepancia argumentada y racional y, además, sus opiniones no afecten a valores elementales individuales como la dignidad de la persona o colectivos, tal, el orden democrático o la pervivencia misma del Estado (unas fronteras estas aceptadas incluso en Alemania, donde el mismo artículo que garantiza la libertad de la ciencia, 5.3, exige al investigador y al docente «fidelidad a la Constitución»).

Otra cosa sería la libertad docente, sujeta a más restricciones porque ha de ejercerse en el marco del servicio público de la enseñanza y por tanto de su delimitación legal o reglamentaria que no puede ignorar el derecho al estudio de los alumnos, es decir, a recibir asignaturas y programas completos.

Dicho esto, anótese que el elemento central y más resistente de la libertad científica y docente es la independencia y la autonomía de sus 
titulares individualmente considerados (a estos efectos, no importa que participen en proyectos colectivos o en docencia compartida), lo que viene reforzado por el hecho de que, en la mayoría de los ordenamientos, el profesor es un funcionario público y por tanto disfruta de las garantías propias de este estatus (y de sus límites: neutralidad política, secreto profesional...). Libertad que ha de defenderse frente al Estado o cualquier otro poder público o privado pero también frente a los poderes internos universitarios y a sus corruptelas, que son inevitables en toda organización compleja ocupada por seres humanos, más cuando los rectores y sus equipos propenden a perpetuarse años y años en los cargos creando núcleos resistentes (y a veces temibles) de poder.

Pero no basta disponer de una trinchera defensiva. En el Estado social moderno (Estado cultural), éste ha de preocuparse además de establecer las condiciones para que la investigación sea posible tanto gracias al intercambio científico entre especialistas como a través de la puesta a disposición de los mismos de aquellos medios personales, materiales y financieros que resulten apropiados. Es decir, ha de crear instituciones adecuadas pues sin ellas no es posible el desarrollo de esas actividades creativas, algunas de las cuales precisan recursos ingentes, y ha de manejar asimismo para el logro de sus objetivos las técnicas de fomento, planificación y coordinación que son habituales en otras responsabilidades públicas. En tal sentido, las universidades, como centros investigadores de primera importancia, como "talleres del futuro», han de verse afectadas por esta dimensión interventora del poder público que es, en cualquier caso, perfectamente admisible siempre que se ejerza con respeto del núcleo indisponible de la libertad investigadora. Adviértase que es en esta nueva modalidad investigadora —en ámbitos sensibles como las ciencias biomédicas y la biología molecular o como los programas atómicos, la investigación electrónica, la investigación de los mares, de los mecanismos de alimentación, de las enfermedades como el cáncer o el sida, de los productos farmaceúticos, etc.- donde las posibilidades de condicionar la libertad investigadora de los especialistas son mayores. De ahí que toda la investigación "por encargo», es decir, "comprada» por instituciones públicas y mucho más por empresas o instituciones privadas, haya de ser analizada con atención y críticamente porque puede, al invadir su entraña misma, comprometer y aniquilar la libertad científica.

Es este un punto crucial de la actual situación en España si se tiene en cuenta que a responsables universitarios les oímos repetir con frecuencia la afirmación según la cual es preciso poner la investigación «al servicio de la sociedad» y de que la Universidad «hunda sus raíces en 
la sociedad que la circunda». Cierto que la Universidad ha de atender demandas sociales pero la Universidad no puede justificarse solamente por los servicios prestados a la sociedad, pues de ser así desaparecería del todo, no ya la libertad académica que garantiza la ley sino la decidida voluntad de ejercerla y la dignidad que ello confiere a la profesión de maestro.

Importa proclamar pues que, ante los riesgos denunciados, la libertad de investigación ha de ser preservada a todo trance en la era de una revolución tecnológica ligada a formas de producción del conocimiento y del saber que están alterando sustancialmente los procesos investigadores.

En tales condiciones es imprescindible recordar que solo existe tal libertad cuando el investigador dispone de libertad y autonomía para plantearse los temas objeto de estudio y, con ellos, las preguntas que cree han de ser resueltas, así como para determinar los métodos de conocimiento que juzgue más apropiados. Es muy conveniente no perder de vista tampoco el hecho de la absoluta soledad e indefensión en que se encuentra el investigador moderno frente a una demanda de su actividad que procede de esos grupos poderosos de intereses ya aludidos a cuyos designios se someten a veces el propio Estado y las instituciones públicas.

Se comprenderá que, ante la importancia de esta libertad y los peligros de todo tipo a que se halla sometida, la idea de la autonomía universitaria queda desdibujada como incapaz que es, por su artificio, de soportar la tensión en que se mueve y se ha movido siempre la institución universitaria. Seguir insistiendo en la autonomía de una Universidad que depende en todo de los medios financieros que a su disposición se ponen desde el exterior y que, además, se ha convertido en una unidad multifuncional en la que conviven elementos muy dispares como bienes variados y heterogéneos, hospitales, servicios asistenciales, comedores, instalaciones deportivas, personas pertenecientes a distintos grupos profesionales, institutos tecnológicos y centros de auténtica investigación con otros que no pasan de ofrecer una digna cualificación profesional, son ganas de tergiversarlo todo en homenaje a una palabra nimbada por el encanto que le atribuye un pasado histórico falsificado, es decir, por sacrificar asuntos graves a un mito.

A mi juicio, insisto, lo relevante es preservar el ejercicio, por los individuos concretos, de sus libertades básicas, de investigación, de cátedra, de expresión... Este es el núcleo del asunto, lo que en verdad vale la pena defender, y no la pretendida posición institucional autónoma de una organización sostenida básicamente con fondos de los contribuyentes que se ha de limitar a gestionar un servicio público. Hoy la Universidad no 
es autónoma pero tampoco es un servicio público (por más que la jurisprudencia constitucional lo recuerde, Sentencia 87/2014) y además con las nuevas Leyes de Procedimiento Administrativo y del Sector público (2015) se las ha colocado en un peligroso limbo jurídico cuyas consecuencias debería algún jurista minucioso aclarar.

Como colmo del despropósito adviértase que son «autónomas» tanto las universidades que encierran en sus venerables muros siglos y siglos de existencia como las creadas anteayer por medio de la aprobación de una ley o de un decreto. Este extravagante modo de proceder acerca la autonomía universitaria a lo que, en el ámbito teológico, se denomina la gracia, un don de la infinita bondad del legislador ordenado al logro de la bienaventuranza, sin méritos ni proporción por parte del así «agraciado».

Lo malo es que, y esto es lo que me importa subrayar, aun siendo como es una idea vacua, ha hecho daño porque se ha convertido en la maleta de doble fondo que ha permitido meter de matute en la vida universitaria mucha mercancía de contrabando y la mayor parte de ella averiada.

\section{El LUGAREÑo EN SU RINCÓN: LA SELECCIÓN DEL PROFESORADO}

Por razones de espacio concretemos nuestra mirada en la selección del profesorado y en los Estatutos de las universidades. Naturalmente no es cierto que la selección de los catedráticos y profesores titulares incumba a la Universidad en virtud de su autonomía porque, si nos molestamos en leer el régimen de ingreso en estas categorías profesionales, veremos cómo existe un procedimiento en el que a la Universidad corresponde tan solo intervenir en una parte del mismo. Y ello vale tanto para el sistema que implantó la ley de 1983 como para el de habilitación de 2001 o el de 2007, para los funcionarios y para los contratados.

Todos han partido de una evidente realidad: la desconfianza hacia la Universidad convocante de la plaza y a lo que esta pudiera hacer con sus tersos y bien planchados poderes autónomos. De ahí las limitaciones a sus facultades y las cautelas de publicidad, controles nacionales, composición de las comisiones juzgadoras y demás. Porque ningún español serio - y el legislador se esfuerza en serlo- puede concebir un modelo de selección entregado a las solas fuerzas decisorias de la Universidad convocante pues, conocedores todos como somos del paño, los peores estropicios y las más abiertas arbitrariedades no tardarían en confirmarse.

Pero, como era necesario llevar alguna ofrenda al altar de la autonomía, se recurrió en la ley de 1983 al exvoto de la designación de dos 
miembros del tribunal juzgador por el rector convocante de la plaza. ¿Qué menos podía darse a la diosa?

Aceptada esta premisa ¿a quiénes iba a designar el rector si no era a los colegas propuestos por el departamento donde habitaba la plaza convocada? ¿Y a quiénes iba a su vez a proponer el departamento aludido si no era a los que prefería el candidato a quien por lo demás se debía que esa plaza hubiera salido al mercado? De donde se concluía que ¡era el propio aspirante quien nombraba a dos de las personas que le iban a examinar!

Es a la autonomía (¿derecho fundamental, garantía institucional, deidad, mito?) a la que ha de imputarse esta forma ágil y natural de allanar un camino a quienes han aspirado a la cátedra que, en otro caso, podría estar poblado de sobresaltos y de trampas. Sin descartar las amarguras.

Se me dirá que el sistema cambió y fue sustituido por el mecanismo de las habilitaciones, tomado del prestigioso y admirado modelo alemán. Cierto, aunque es lástima que a nuestro legislador se le olvidara prohibir las promociones internas en la propia Universidad del aspirante que es la seña de identidad de la Universidad alemana desde su parto en la mente de Humboldt, allá en el paritorio instalado en Berlín a principios del siglo XIX.

Ahora bien, quien era «habilitado» o — después- «acreditado» (a partir de 2007) en unas pruebas nacionales no ha tenido ni mucho menos asegurado el puesto docente y remunerado en la Universidad, pues para conseguir su asiento en los presupuestos públicos se han necesitado y se necesitan otros requisitos. Puede ser que disponga del apoyo de la Universidad de la que procede: estamos ante un afortunado pero en su fortuna muchas veces influyen circunstancias ajenas a la valía intelectual como son las buenas relaciones con los miembros del departamento (no solo con su director), con aquellos que integran los múltiples comités y comisiones que decoran el barroco espacio universitario, y finalmente con el rector (o su lugarteniente, el vicerrector de profesorado). Esto último, la puntería a la hora de emitir el voto en las elecciones rectorales, es, con más frecuencia de la deseada, determinante. Quien se halle así respaldado, asciende en su Universidad de procedencia sin problema alguno y en medio de parabienes y elogios. Pero quien no cuente con estos apoyos, aviado está.

El sistema puesto en pie en 2007 — hoy vigente- es ya decididamente perverso.

Por primera vez en la historia de España se han suprimido de forma general las pruebas públicas para ingresar en los escalafones con la excepción de los concursos internos de las Universidades para las per- 
sonas que ya se encuentren acreditadas. Podrá ser tal prueba algo muy serio o, lo que es más probable, un simulacro, pero si la elección de esta alternativa se deja — como es el caso- a esas chapuzas normativas que son los Estatutos — de los que luego me ocuparé-, las posibilidades de que se instale la chapuza son crecidas.

La fase de «acreditación» tiene carácter nacional y sustituyó al sistema de «habilitación» porque este resultaba muy caro, como si no fuera caro mantener puestos y puestos de vicerrectores y colaboradores «a dedo» de estos y nadie ha propuesto suprimirlos. Y como si no fuera caro pagar miles de viajes de cargos y más cargos, viajes a la nada de las comisiones, comités y demás vacuidades.

Por tanto, la supresión de las pruebas públicas ha contribuido a la degeneración del sistema como era de esperar. Sobre todo si se tiene en cuenta que las comisiones están compuestas por miembros designados de manera misteriosa o, cuando menos, opaca: adiós a los sorteos por los que clamábamos en el franquismo los jóvenes aspirantes, deseosos de acabar con las corruptelas debidas a la mediación de las autoridades ministeriales en la composición de los tribunales. Que, entonces, era con todo parcial y muy medida.

Con ser esto malo, no es lo peor. Porque, a lo largo de los tiempos, han sido especialistas los llamados a reclutar a quienes habían de acompañarles y, en su día, sucederles en el ejercicio de la docencia universitaria: los pediatras seleccionaban a sus jóvenes colegas, y lo mismo los físicos o los lingüistas o los químicos. Esta antigualla es desterrada creando unas cuantas ramas del conocimiento: Artes y Humanidades, Ciencias, Ciencias de la Salud, Ciencias sociales y jurídicas, Ingeniería y Arquitectura.

Es evidente que el sociólogo presente en la comisión de ciencias sociales y jurídicas o el experto en econometría nada saben de derecho mercantil por lo que los expedientes irán a parar normalmente a quien en ella ostente (u ostenten) la condición de jurista. Pero tal jurista puede no ser un mercantilista sino un reputado constitucionalista que ni de lejos sigue las publicaciones de derecho mercantil. Ayuno de tales conocimientos, se permite recurrir a expertos del ámbito científico correspondiente. Expertos de nuevo designados, no sorteados.

Cuando todo el material vuelve a la deliberación de los comisionados, serán ellos con sus calificaciones los competentes para «acreditar» o rechazar la acreditación solicitada.

Es decir, que lo que hasta ahora había sido función de cinco o siete especialistas de una disciplina universitaria, con la acreditación se confía el procedimiento selectivo a personas carentes de los conocimientos 
adecuados para juzgar la labor de un joven que aspire a ser acreditado como «profesor titular» o como «catedrático». Porque es preciso aclarar que en los trabajos académicos se hila fino y que cualquier tesis doctoral aborda asuntos de detalle que solo pueden ser valorados por quienes dedican su vida y sus esfuerzos a una concreta materia. Para saber si un libro sobre la reducción del capital en las sociedades anónimas es original, es preciso conocer cuál es el estado del tratamiento de la cuestión en la bibliografía existente, los problemas planteados, las soluciones propuestas, etc. Es decir, se necesita ser un especialista en derecho mercantil.

Tal disparate, que muchos denunciamos apenas vimos aparecer su coleto en el Boletín, se ha cambiado recientemente de forma leve pero, en todo caso, es tal la acumulación de expedientes que han de ser tratados con la normativa anterior que su vigencia puede decirse que goza de buena salud.

Como además no hay plazas limitadas, todo ha conducido a la proliferación de «acreditados» siendo ya varios miles los que deambulan y vagan por los espacios universitarios. Cualquier día acamparán como los «indignados» que son de nuestras Universidades, perjudicados por los «recortes» presupuestarios de suerte que las plazas, cuando salen, lo hacen a cuentagotas y siguiendo criterios a veces — las menos- objetivos, a veces extravagantes.

Si tienen suerte, lo que en la mayoría de los casos consiste en contar con el apoyo del rector, se somete el candidato a una prueba interna y local. Dejada su regulación a los Estatutos y normas universitarias, como ya sabemos, podemos imaginar el producto que sale de este amasijo.

Hay otros profesores que se vinculan a la Universidad por medio de un contrato. ¿Sin pruebas? No. El legislador, que como sabemos rinde pleitesía verbal a la autonomía pero no se fía ni un pelo de las autoridades locales pues sabe que sin cortapisas son capaces de montar un espectáculo emparentado con las piezas teatrales cómicas, atribuye a agencias de calidad la evaluación de quienes aspiraran a vincularse a la institución universitaria por esta vía laboral.

Junto a la Agencia nacional (ANECA) han florecido las ANECAS de las comunidades autónomas (es decir, en cada una de ellas hay una ANECACA que en Cataluña ha servido para «desconetarse» del Estado español) diferenciadas por el solo hecho de que el estampillado de aquella es válido en todo el territorio nacional mientras que el de estas queda restringido al de su propio territorio. Pura falacia porque las posibilidades de traslado entre las universidades españolas prácticamente han desaparecido como consecuencia de la autonomía universitaria. 
Son estos (la vía funcionarial y la laboral explicadas) los mecanismos aprestados para que un ciudadano pueda dictar sus lecciones, con todas las bendiciones oficiales, en la Universidad autónoma española.

Una Universidad que se ha hecho, a fuerza de autonomía, penosamente lugareña porque en la Universidad española actual se propende a confundir la libertad universitaria o su autonomía con la libertad y la autonomía corporativa de los propios universitarios.

III. LA LEY DEL EMBUDO: ESTATUTOS Y REGLAMENTOS DE LAS UNIVERSIDADES

Otra seña de identidad de la autonomía ha sido la aprobación de los Estatutos. Todos son iguales, su factura técnica suele ser penosa pero las autoridades universitarias y algunos colegas se distraen mucho entregados a la estéril labor de su elaboración y tramitación. Ahora bien, la fecundidad normativa de las Universidades no se contrae a la redacción de los Estatutos sino que se extiende a los reglamentos. Mundo barroco el de los reglamentos universitarios, no hay Universidad española que no tenga aprobados centenares de ellos, muchos en permanente reforma, por los equipos rectorales que vienen, por los que se van, por los que permanecen, todo ello en medio de un frenesí legislativo que dice mucho a favor de la fe en las virtudes de la norma de los responsables universitarios. Conmovedora lealtad al Estado de derecho.

Reglamentos hay de muchos tipos y así puede decirse que no hay sector de la vida universitaria que no cuente con su reglamento. Quien tenga apetito de reglamentos encontrará en nuestras universidades el alimento adecuado y nunca se sentirá defraudado. Siempre que logre conocerlos porque ha sido tradicional que buena parte de ellos no se haya publicado en boletín oficial alguno, habiendo quedado, como se decía en el Antiguo Régimen, in scrinio péctore, una práctica perversa de la que se sale a duras penas.

Pero la existencia de tanta norma jurídica no siempre implica la existencia de adecuadas garantías en la convivencia universitaria. Ni que la objetividad del derecho resplandezca por doquier y emita por aquí y por acullá su benéfico influjo. ¿Por qué se produce este fenómeno? Para explicarlo voy a recurrir al tropo: a mí se me antoja que el ejercicio de la potestad reglamentaria por parte de las universidades produce algo semejante a una alcachofa, con muchas hojas (preceptos, artículos, disposiciones transitorias, contradictorias y demás) que recubren y guardan en su intimidad el corazón, lo más sabroso y carnoso, representado por 
la discrecionalidad de quien ha de aplicar la norma (rector, director de departamento o cualquier otra autoridad competente). Todo lo demás es hoja caduca cuando no hojarasca.

A esta discrecionalidad se une algo peor. Los juristas sabemos que nada hay más eficaz para no aplicar una norma que disponer de muchas y muy variadas. Pues bien, en el ámbito universitario esta regla no podía dejar de encontrar su adecuada aplicación que conduce al espacio de la arbitrariedad. Y es que la mayoría de los reglamentos, por las especiales relaciones de poder existentes en la Universidad, no se aplican (lo mismo ocurre en otros sectores del ordenamiento, el universitario no es una singularidad) pero están ahí, dormidos, yacentes, aparentemente inertes, y, sin embargo, de pronto, abren un ojo, se desperezan, se despabilan, se yerguen como un aparecido y con su coraje intacto se disponen a ser aplicados... a un caso particular. Que esta diligencia excepcional y repentina, imprevista, encubre normalmente el otorgamiento de un privilegio o la perpetración de una venganza es cosa de todos sabida, pero nadie se atreverá a denunciarlo.

Lo razonado hasta aquí permite concluir que la autonomía universitaria, incorporada con la mejor intención por los padres de la Constitución, no existe más que en la forma de un singular corporativismo, a todas luces inconveniente y, por ello, vitando.

La legislación universitaria es un bosque espeso en el que el árbol más sano y de mejor crecimiento es ese de hoja perenne que representa la voluntad del rector o de su equipo (nombrado a dedo), voluntad solo limitada por los intereses corporativos y sindicales más el control que esperemos se afiance en el futuro ejercido por las comunidades autónomas a través de la fiscalización de los dineros.

Porque, si dejamos a su aire a los rectores, y a salvo alguna excepción, seguiremos en la certidumbre de que en la Universidad no hay leyes ni reglamentos, lo que hay son amigos y enemigos. $\mathrm{O}$ ese indiferente al que se aplica con todo rigor un precepto dormido de la legislación vigente, entre la que ocupa privilegiado espacio la ley del embudo. Un embudo que, distante y engreído, propende a afirmar con determinación su señorío sin fronteras.

\section{Europa o El LUGar donde SE PIERde El PElo De LA DEHESA}

Si contemplamos la Universidad desde Europa lo primero que debe ser destacado es que, como tal, no figura entre las competencias de las 
instituciones europeas. Desde 1992 el Tratado se limita a decir que «la Comunidad contribuirá al desarrollo de una educación de calidad fomentando la cooperación entre los Estados miembros y, si fuere necesario, apoyando y completando la acción de estos en el pleno respeto de sus responsabilidades en cuanto a los contenidos de la enseñanza y a la organización del sistema educativo, así como de su diversidad cultural y lingüística» (las cursivas son mías). Después, el actual Tratado de Funcionamiento ha añadido que «en la definición y ejecución de sus políticas y acciones, la Unión tendrá en cuenta las exigencias relacionadas con la promoción de... un nivel elevado de educación y formación» y, por su parte, en la Carta de Derechos Fundamentales se acoge el «derecho a la educación».

Siendo esto así, siendo indudables estos datos nomativos, no debemos dejarnos engañar por su naturaleza esquemática.

Porque lo cierto es que Europa pinta y pinta mucho, lo mismo que pinta mucho el contexto internacional en que las universidades - las nuestras y todas - se mueven en un mundo en el que las fronteras de la comunicación intelectual y profesional tienen los días contados. Por tanto, el horizonte europeo y el del diálogo mundial de la ciencia y de los conocimientos es un horizonte risueño que solo puede molestar a los colegas apegados a su terruño, dicho en plata, a los paletos. Por tanto, quien quiera seguir adornado con el pelo de la dehesa, quien quiera seguir en la Universidad ignorando idiomas y desconociendo lo que sus colegas hacen por aquí y por allá, se convertirán en piezas de un mausoleo aunque todavía tengan cierta apariencia de vida y por ello no se hallen enteramente bajo tierra.

Pensemos, para corroborar estas afirmaciones, en los programas puestos en pie desde Bruselas. De entre ellos el más conocido es «Erasmus» que, desde 1987, ha movido a millones de estudiantes. Casi cincuenta mil profesores y personal administrativo se han beneficiado asimismo de ayudas para formarse o impartir docencia en centros extranjeros (no estrictamente europeos). España figura como uno de los países que cuenta con más estudiantes Erasmus, pues es un destino muy codiciado. Comprobar hoy cómo personas que ocupan puestos muy relevantes en sus sociedades han sido en su juventud estudiantes «Erasmus» es muy satisfactorio y refleja la magnitud del empeño.

Junto al programa «Erasmus» hay que citar el más moderno «Erasmus $+»$, que tiene como fin la inversión en educación y como medios la integración de otros hasta ahora separados en ámbitos como la educación superior (Erasmus, Erasmus Mundus, Tempus ...), educación y formación profesional (Leonardo da Vinci), educación de adultos (Grundt- 
vig), estudios sobre la integración europea (Jean Monnet). Entre 2014 y 2020 se espera que sean varios millones de personas - estudiantes y profesores- las que se beneficien de estas acciones.

Singular importancia cobra en este contexto la política de investigación y desarrollo tecnológico amparada por el Tratado de Funcionamiento, pues «la Unión tendrá por objetivo fortalecer sus bases científicas y tecnológicas mediante la consecución de un espacio europeo de investigación en el que los investigadores, los conocimientos científicos y las tecnologías circulen libremente».

Actualmente está en vigor el Programa Marco, cuyo horizonte es el año 2020, y a cuyo amparo se han de financiar —más de ochenta mil millones de euros hay previstos- miles de iniciativas de los investigadores europeos. Cualquier proyecto en el que colabore la Unión cuenta con la participación de universidades, centros de investigación, empresas o personas individuales de diferentes Estados miembros pero también de asociados y de terceros países.

Como diputado en el Parlamento Europeo y miembro de su Comisión de Industria, Energía e Investigación he participado a lo largo de la legislatura 2009-2014 en decenas de debates sobre ese Programa Marco y he podido constatar tanto su fecunda incidencia en el esfuerzo investigador de sus siete ediciones anteriores como sus fallos entre los que destacan las quejas continuas por su funcionamiento desesperadamente burocratizado.

Fuera de la Unión Europea, estrictamente considerada, vive el Espacio Europeo de Educación Superior cuya andadura se inició en 1999 con el Proceso de Bolonia, un intento de armonizar y coordinar los sistemas educativos europeos. En tal espacio se hallan integrados no solo los países de la Unión sino otros como Rusia, Turquía o Suiza...

Con él se han instaurado novedades como el «crédito» (una palabra ciertamente horrible) que mide las horas de trabajo y que pretende reducir las de clase teórica en beneficio de prácticas tuteladas. Asimismo se ha generalizado la división de la educación superior en dos ciclos, el grado inicial y el postgrado de especialización. En fin, un sistema de "acreditación» ha de controlar la calidad de los centros educativos y su adecuación a los requisitos de este espacio europeo. En España nos hemos metido en él a partir de 2007 con las reformas de las leyes correspondientes y el enorme lío que todo ello ha provocado.

Uno de sus objetivos es fomentar la movilidad de los estudiantes tanto dentro de Europa como en otras partes del mundo y especialmente la movilidad dentro de España mediante un sistema de reconocimiento y acumulación de créditos que permite que los cursados en otra Uni- 
versidad sean reconocidos y puedan ser incorporados al expediente del alumno.

Tal movilidad está beneficiando ya también a muchos profesores que pueden investigar y aun enseñar en el extranjero. Ahora solo falta que se facilite la movilidad de los profesores en el interior de España pues han desaparecido los concursos de traslado y el ascenso en universidades distintas de aquellas en las que se han cursado los estudios es una ilusión. El profesor universitario español tiene hoy la misma movilidad que el doncel de Sigüenza.

Este proceso de Bolonia cuenta con detractores y entusiastas partidarios. A mi juicio, son muchos los fallos no tanto de diseño como de ejecución por las autoridades nacionales, en España agravados por el embrollo - en parte gratuito- que propicia la estructura autonómica. No me gusta tampoco que se haya perdido el tradicional título de licenciado, sustituido por otros fruto de un papanatismo de origen americano que es sencillamente ridículo.

Pero me quedo con lo positivo que es el reconocimiento de que la educación superior ya ha trascendido los espacios nacionales y, por ello, ese universitario aldeano que todos hemos conocido tiene sentenciada con la pena capital la difusión de su rusticidad. Airearnos con el intercambio científico, con las experiencias educativas foráneas, con la participación en encuentros en los que sea preciso manejar lenguas, todo ello conformará una Universidad mejor porque lo bueno que hoy tenemos precisamente procede de esta apertura al exterior que con Bolonia se refuerza e intensifica aunque no es una invención reciente (viene de la Junta de Ampliación de Estudios y de otras iniciativas de las que muchos nos hemos aprovechado).

\section{EL HONOR PERDIDO DEL CONSENSO}

Por consiguiente, hoy las circunstancias fuerzan ya a hacernos más cosmopolitas y a recordar que los orígenes de la Universidad —precisamente en Bolonia- fueron muy poco provincianos.

Mi tesis es, pues, que desde fuera, desde Europa pero también desde Corea o China, desde América, nos han de venir las grandes mudanzas llamadas a cambiar radicalmente la Universidad.

Hay aspectos, sin embargo, de nuestra Universidad, de la española, que sólo nosotros podremos reformar para acomodarla a la altura de un tiempo nuevo cruzado de novedades, certezas y enigmas. 
Ahora bien, la pregunta inquietante es la siguiente: ¿merece la pena intentar esa reforma autóctona de la Universidad española? Porque lo que sabemos es que las aprobadas desde los años ochenta nos arrullaron con la ensoñación de la autonomía y de la democracia y, al despertar, lo que hemos encontrado entre nuestras manos es un artefacto sindical y corporativo.

¿Qué hacer para corregir esta situación? Y lo más preocupante: ¿permite nuestra arquitectura constitucional y nuestras costumbres políticas aprobar medidas para enmendar el rumbo de la Universidad?

Mi aprensión y mis temores son máximos sobre todo si se tiene en cuenta que — según oímos machaconamente-cualquier intento deberá contar con un amplio consenso, no solo entre las fuerzas políticas sino con todos los protagonistas del escenario: profesores, alumnos, funcionarios, sociedad en general. Solo así se podría llegar a un resultado plausible, aceptado y duradero.

Reputo un error de gran alcance tal afirmación.

Recordemos que la invocación al consenso emparenta con la eterna cuestión de la legitimidad del poder y de la búsqueda del huidizo interés general (los grandes bocados de la filosofía política y de la filosofía a secas desde Platón para acá). Cuestión que intentó ser resuelta por el liberalismo y el Estado democrático al identificar al poder legislativo como el depositario de la voluntad popular y por tanto como el garante de esa legitimidad, definidor al tiempo del interés general. Pero el Estado democrático degenera en Estado de partidos, más exactamente en Estados mangoneados por las cúpulas de los partidos, lo que obliga a buscar nuevas legitimidades, llamadas a ser asumidas e incorporadas en las estructuras históricas tradicionales.

En tales circunstancias, cuando ya ha perdido vigencia el refrán allá van leyes do quieren reyes, la idea del consenso se nos ofrece como un talismán: el diputado, el ministro, el alcalde, el rector de una universidad son autoridades que, a las preguntas sobre sus intenciones en la resolución de tal o cual asunto, contestan asegurando que actuarán siempre «por consenso». El «diálogo» es el ábrete sésamo de cualquier acción de gobierno y de cualquier discusión política. Un diálogo permanente, fluido, ininterrumpido y rico, como río en ejarbe, recién estrenado el deshielo. El consenso como el diálogo es una encantadora disposición de ánimo, pero, para sentarse a la mesa e iniciarlos, es aconsejable partir de ciertas convicciones previas expresadas con rigor, a cambiar o matizar pero solo si las razones que se ofrecen de contrario resultan más poderosas.

Dicho de otra forma: el diálogo y el consenso no pueden convertirse en el taparrabos de quien no tiene rabo que tapar. 
Porque proceder de este modo es confundir el procedimiento con la sustancia, el camino con la posada, el humo con el fuego. Aunque esto es así a poco que se medite seriamente en ello, lo cierto es que, como digo, el tal consenso es palabra nimbada por la gloria, evocadora de un mundo arcádico y armonioso. Que el problema quede sin resolver o resuelto a medias (a veces en la forma de abominable chapuza) a casi nadie le preocupa porque es muy probable que, cuando se vean los costurones de la solución adoptada, habrá pasado el suficiente tiempo como para que los protagonistas hayan sido sustituidos por sus sucesores en el imparable trasiego biológico de las generaciones.

El consenso, pues, como amuleto que, cuando se acepta como forma de un rito renovado, está dando cuerpo a una forma distinta de legitimidad política. El político actual apelará al consenso social —cuanto más amplio, mejor- porque se halla a la búsqueda de ese nuevo manantial de la autenticidad democrática que ya el Parlamento parece haber perdido de forma alarmante incluso a sus ojos. Pero tal consenso social, ¿en qué yacimiento se halla? ¿Cómo es posible dar con él? Porque tengo para mí que el consenso con «los sectores interesados» acaba, en la realidad, sentando a la mesa a unos pocos, en rigor muy pocos «interesados», siempre sujetos sospechosos: los que gozan de mayor influencia social, quienes más capacidad tienen para alterar el orden público o cuentan con más posibilidades de acceso a los medios de comunicación, o simplemente los más entrenados en el arte de enredar... No es extraño que, sobre esta base, los acuerdos que puedan trabarse adolezcan casi siempre de falta de rigor y de seriedad porque a menudo propenden a olvidar o a abandonar en una peligrosa penumbra al interés público considerado en su dimensión más limpia y amplia.

Creo, por el contrario, que el gobernante, y más si desea cambios, debe ser un señor con algunas convicciones y el vigor suficiente para aplicarlas si dispone del respaldo democrático adecuado en las instituciones representativas. O sea, un señor - o señora- que por las mañanas recuerde que Mendizábal no dialogó ni consensuó con los frailes la desamortización.

Al menos se impone reivindicar el disenso.

En el espacio universitario pretender contentar a rectores, personal encargado de las tareas administrativas o de la limpieza, profesores y jóvenes estudiantes — que son usuarios del servicio público- todo ello así junto y de corrido es lisa y llanamente pensar en lo excusado.

Es entre las fuerzas políticas donde hay que buscar los acuerdos, por lo que sería conveniente que quienes ostentan la legitimidad democrática fueran conscientes del alcance de lo que llevan entre ma- 
nos. Para ello es imprescindible, de un lado, que el político sea seleccionado por métodos cuidadosos que valoren sus reales capacidades, es decir, casi lo contrario de lo que ahora se estila; de otro, que tal político contara, para adoptar sus decisiones, con el asesoramiento de personas acreditadas por sus conocimientos y su prestigio profesional así como por esas canas que le alejan de los compromisos mundanos, apagados ya los ardores que suelen consumirnos en la cucaña de la vida.

Pero aquí nos volvemos a encontrar con la tozuda realidad porque resecas como están las tierras de la política española, el abono que supondría para ellas el apoyo de expertos ya se ha administrado en el pasado sin que haya podido apreciarse el nacimiento de buenos frutos. El último ejemplo es la Comisión de once expertos que designó el Gobierno en 2012. Hicieron su trabajo, que constituyó una buena base para seguir discutiendo sobre la Universidad, lo entregaron al ministro del ramo quien, solícito, lo guardó cuidadosamente en una gaveta y hasta hoy. Nadie le ha prestado la más mínima atención.

Por tanto, mi afligida conclusión es que cualquier reforma universitaria que se acometa, si tenemos en cuenta las características nacionales, o será una chapuza o se parecerá mucho a esta forma degradada de afrontar la realidad. Seguiremos por lo tanto con un sistema de selección del profesorado trufado de intereses gremiales que milagrosamente selecciona algunos buenos profesionales y con un gobierno universitario confiado a aficionados y por tanto inadecuado para regir instituciones tan intrincadas como son hoy las Universidades y seguiremos con los complejos que engendra la «democratitis» y la participación de estamentos variopintos que crea ineficaces (y grotescos) sistemas polisinodiales.

¿En qué confiar? ¿Se impone la desesperanza? No, ya he señalado que desde fuera se irán imponiendo los cambios que han de mudar el paño universitario y, en tal sentido, el Espacio europeo de la Enseñanza y el de la Investigación serán determinantes para concebir nuevos modos, nuevos comportamientos.

¿Cómo no va a cambiar su trabajo el profesor cuando advierta que los alumnos pueden elegir, sin especiales complicaciones, entre acudir a su clase o a la de otro que se encuentra a miles de kilómetros?

¿Cómo no va a cambiar la mentalidad del alumno cuando se percate por fin de la dificultad que entraña conocer bien un oficio en un mundo competitivo y sin fronteras? ¿No se darán cuenta de que es inútil pedir aprobados "por compensación» y de que es mejor apretar los codos en las bibliotecas y laboratorios que entregarse a la rutina perezosa o a la 
zafiedad de los botellones? ¿No serán más sensibles y adoptarán conductas más respetuosas con la cultura y con los libros?

Solo de esta forma paulatina que, sin pausa, se ha de imponer, transformando el trabajo de los profesores y de los estudiantes, transmutando los materiales caducos y convirtiéndolos en cenizas del tiempo pasado, habremos conseguido cambiar la organización que los engloba, o sea, la Universidad.

$\mathrm{O}$, al menos, la parte de ella que de veras importa. 
